\title{
MIGRACIÓN Y SÍNDROME DE ULISES: SER NADIE EN TIERRA DE NADIE
}

\author{
MIGRATION AND ULISSES SYNDROME: BEING NOBODY IN \\ NOBODY'S LAND
}

\author{
Adela Reig-Botella \\ Miguel Clemente Díaz \\ Inmaculada Sangiao Bastida \\ Universidad de A Coruña. A Coruña/España \\ adela.reig@udc.es \\ miguel.clemente@udc.es \\ sangiaoinma@gmail.com
}

Recibido/Received: 27/04/2018

Modificado/Modified: 08/07/2018

Aceptado/Accepted: 22/09/2018

\section{RESUMEN}

Nos enfrentamos en la actualidad a la peor crisis de refugiados desde la Segunda Guerra Mundial. Se trata de un proceso constante, que se incrementará en el futuro y se enmarca en los diferentes movimientos migratorios que desde hace décadas estamos viviendo debido no solo a conflictos bélicos, sino también a motivos económicos, políticos y climáticos. Este trabajo trata de analizar los riesgos psicosociales a los que se enfrenta la población migrante en situaciones extremas focalizando el análisis en el síndrome de Ulises: síndrome del inmigrante con estrés crónico y múltiple. Los resultados evidencian la necesidad de incorporar este análisis a los programas de acogida e integración social y laboral, puesto que la forma en la que recibimos y protegemos a la población migrante marcará la diferencia entre su inserción o su inadaptación.

\section{PALABRAS CLAVE}

Migración; asilo; riesgos psicosociales; síndrome de Ulises; integración; inadaptación.

\section{SUMARIO}

1. Introducción. 2. Contexto actual. 3. 3. Riesgos psicosociales asociados a la inserción laboral de la población migrante. Síndrome de Ulises. 4. Conclusiones. Bibliografia.

\footnotetext{
ABSTRACT

We are facing the worst refuge crisis since World War II. This is a constant process, that will increase in the future and it is framed into the several migratory movements that we are living since decades not only because of war, but also due to climatic, political and economic reasons. This article tries to analyze the psychosocial risks that migrant people face in extreme situations focusing the analysis in Ulysses syndrome: The syndrome of migrant people with chronic and multiple stress. The results show the need of incorporating this analysis into the social and labor integration programs because the way we receive and protect migrant people will represent the difference between their integration and their maladjustment into the new society.
} 


\section{KEYWORDS}

Migration; refuge; psychosocial risks; Ulysses syndrome; integration; maladjustment.

\section{CONTENTS}

1. Introduction. 2. Global current situation of refugees and migrants. 3. Psychosocial risks related to labor access of migrants. 4. Conclusions. References.

\section{INTRODUCCIÓN}

La palabra asilo es de origen griego y está compuesta de la partícula privativa "a" y el verbo sylao, que significa capturar, violentar, devastar; pasó al latín como asylum- $i$, sitio inviolable y literalmente significa "sin captura, sin violencia, sin devastación".

Podemos entender que el exilio es de alguna manera un modo de muerte, por la vida pasada que el individuo deja atrás; pero al mismo tiempo y en compensación podemos entender el asilo como la esperanza del acceso a una nueva vida.

La práctica del asilo ha existido durante siglos y nace fundamentalmente de las costumbres de los pueblos nómadas, que, obligados o acostumbrados a transitar, lo aluden con asiduidad, a través de la práctica de la hospitalidad. Dos grandes pueblos, en su origen nómada, el musulmán y el judío, contienen remarcables ejemplos de hospitalidad, práctica que es incorporada a sus leyes.

En Europa, la aplicación de la Convención sobre el Estatuto de los Refugiados de 1951 es un aspecto fundamental del Sistema Europeo Común de Asilo. Con la adopción de esta normativa, los Estados miembros comenzaron el proceso de modificación de sus legislaciones nacionales.

Para asegurar el manejo apropiado de las migraciones, es vital reconocer las notables diferencias de los flujos migratorios dentro del continente africano, así como desde África hacia Europa, para poder brindar respuestas diferenciadas (Adepoju, 2016:1). A pesar de que los refugiados y migrantes a menudo usan las mismas rutas, la situación de los refugiados es diferente, ya que ellos no pueden regresar a sus países natales, y el hecho de que Europa les niegue el derecho de entrada podría tener consecuencias letales para ellos. (Flahaux et al., 2016:2).

Las iniciativas que buscan fortalecer la autosuficiencia y las oportunidades económicas deben ir de la mano del desarrollo de sistemas sólidos de asilo y programas de protección, incluso en los países de tránsito (Martin, 2016:63).

Asimismo, los enfoques para combatir el tráfico y la trata de personas no deben ser perjudiciales para el derecho de asilo y sólo será verdaderamente exitoso este último si las vías legales de acceso están disponibles para los refugiados. La forma en la que recibimos y protegemos a la población migrante marcará la diferencia entre su inserción o su inadaptación, por lo que debemos estar preparados para gestionar esta situación.

El objetivo general de este artículo es mostrar la urgencia de la revisión y actualización de las políticas y programas de acogida de migrantes en nuestro país dada la grave crisis migratoria que está afrontando Europa en los últimos años, señalando especialmente la importancia de la incorporación de la prevención de la aparición del mencionado síndrome de Ulises en los programas de acogida.

El tipo de investigación utilizado es el descriptivo, realizando una revisión documental, 
tratándose por tanto de un método no experimental basado en la revisión exhaustiva de los textos más actuales y relevantes publicados al respecto y revelan que si bien desde hace algunos años en el ámbito de la psiquiatría se han empezado a estudiar los trastornos relacionados con la migración y se han realizado investigaciones sobre estrecho vínculo que se manifiesta entre el estrés social y la salud mental, todavía es escaso el número de estudios realizados en España para determinar la prevalencia de las patologías mentales en población inmigrante.

\section{CONTEXTO ACTUAL}

\subsection{Percepción actual de la inmigración: la importancia del tratamiento mediático}

En las Recomendaciones sobre estadísticas de las migraciones internacionales de las Naciones Unidas podemos encontrar la definición del migrante internacional como cualquier persona que ha cambiado su país de residencia habitual y distinguen entre "migrante por breve plazo" (aquel que ha cambiado su país de residencia habitual durante al menos tres meses, pero no durante un plazo superior a un año) y "migrante por largo plazo" (aquel que lo ha hecho durante al menos un año) aunque no todos los países utilizan esta definición en la práctica.

La utilización de diferentes conceptos y definiciones, y métodos de recopilación de datos, obstaculizan la plena comparabilidad de las estadísticas nacionales sobre migrantes internacionales. (Informe OIM: 31).

Podemos identificar diversos factores psicosociales que explican las actitudes de rechazo hacia los inmigrantes y que conducen a procesos de discriminación y exclusión social, como los factores sociodemográficos, la ideología política, la percepción de amenaza social o cultural, o el nivel de contacto con los inmigrantes.

Un factor situacional que contribuye a generar imágenes de discriminación y exclusión social a nivel colectivo es la acción informativa de los medios de comunicación (Van Dijk, 2003; Van Klingeren et at., 2015: 269). El enfoque dominante en la mayoría de las noticias asocia inmigración con delincuencia, mafias, organizaciones delictivas, detenciones de inmigrantes y las actuaciones terroristas atribuidas a éstos (Igartua, Muñiz y Otero, 2005)

Según Perse (2001), las personas otorgan importancia a las noticias a partir de que éstas se encuentren situadas en lugares destacados dentro de un diario o en un informativo televisivo, de que se les conceda mucho espacio en los mismos, se acompañen de fotos o videos o porque éstas aparezcan en titulares. Y según Igartua et al. (2004), los contenidos de los informativos no solo fijan la agenda pública, sino que también dictan al público de una forma más o menos implícita la forma en la que deben pensar sobre ciertos asuntos (Centelles, 2015).

En cuanto a las imágenes proyectadas de los inmigrantes predominan las de carácter negativo y dramático: mujeres, niños y jóvenes, inmigrantes detenidos, heridos o muertos; y tienen una presencia menor las que ofrecen una visión positiva de la inmigración: trabajando, en situación de ocio, de representantes de asociaciones de inmigrantes (Blinder, 2015: 81).

Existen claras diferencias en el tratamiento de la inmigración entre la prensa y la televisión; según Igartua, Muñiz y Cheng (2005), el medio televisivo destaca por su mayor grado de sensacionalismo, y por el contrario la prensa ofrece un mayor número de enfoques temáticos por noticia y una mayor diversidad de los mismos (Martínez, 2017: 94).

Esta actuación mediática tiene consecuencias cognitivas en la opinión pública. El emplazamiento privilegiado de noticias negativas sobre la inmigración en la prensa y los 
informativos televisivos añaden una visibilidad negativa de la inmigración, convirtiendo un proceso social en un problema.

Existen investigaciones que demuestran que la integración social de los inmigrantes está condicionada por la percepción que éstos posean de la discriminación y exclusión social de la que son objeto por parte de la sociedad de acogida (Basabe, Zlobina y Páez, 2004) por lo que podemos señalar la acción informativa de los medios de comunicación como un factor situacional que contribuye a generar imágenes de discriminación y exclusión social a nivel colectivo, ya que se potencia una imagen problemática de la inmigración (Laczlo, 2017: 9)

Teniendo en cuenta la amplia cobertura negativa que los medios de comunicación hacen de la migración, y su grado de influencia, cabe preguntarse cómo deberían los medios de comunicación tratar un tema tan complejo y diverso admitiendo que los medios de comunicación, en todas sus formas, desempeñan un papel preponderante en el debate público.

Por otra parte, a medida que los medios sociales y digitales se multiplican y diversifican, también se plantea el problema de cómo lidiar con los contenidos falsos o engañosos (Álvarez et al., 2015: 5).

Los medios sociales permiten acercarse fácilmente con mensajes y material políticos a determinados públicos, utilizando técnicas que pueden ser difíciles de detectar o analizar. Este tipo de microsegmentación de un público persuasible, que ha sido identificado y contactado a través de su actividad en los medios sociales, es un fenómeno en expansión (Bennett, 2016: 261).

\subsection{Actitudes hacia la inmigración en Europa}

Diversos autores han analizado las razones que influyen en el racismo y la intolerancia hacia la inmigración en Europa, así como la diferencia entre el racismo existente en otros países como Estados Unidos en los que tradicionalmente la inmigración forma parte de la construcción de la identidad del país, y nuestra Europa, en la que los Estados se definen como grupos étnicos diferenciados (Citrin y Sides, 2008).

Debemos ser cautos a la hora de proponer una definición de este nuevo racismo al que se enfrenta la sociedad, el vinculado a la primera cuestión, e incluir en esta definición una explicación de los procesos psicosociales que llevan a las personas a ser reticentes hacia lo diferente puesto que, aunque el racismo basado en el color de la piel todavía existe de forma expresa, en la actualidad la xenofobia se define a partir de diferencias culturales diversas, que no solo incluyen este racismo evidente, sino también un nuevo racismo latente que no se manifiesta socialmente por resultar políticamente incorrecto, pero que existe y persiste (Rathod, 2016: 861).

Existe un amplio consenso de que es más probable que tengan actitudes racistas las personas mayores que los jóvenes, y que un nivel de estudios mayor reduce las probabilidades de desarrollar actitudes racistas o al menos su expresión (Ceobanu y Escandell, 2010). En cuanto al género, los hombres son algo más racistas que las mujeres. Hay otros estudios que muestran que las personas más religiosas rechazan más a los inmigrantes, especialmente a los que no son de la misma religión (Billiet, 1995). Y según la posición ideológica, las personas de extrema izquierda e izquierda toleran más a los inmigrantes que los de derechas y extrema derecha (Seminov et al., 2006)

Si se efectúa una comparativa entre países de la Unión Europea se puede comprobar que Chipre es el país más claramente racista, siendo Suecia el país más tolerante. También se constata que la tasa de inmigración influye en las actitudes hacia los inmigrantes: a mayor volumen de inmigrantes en un país, se genera mayor rechazo (Centelles, 2015: 50). 


\subsection{La frontera sur de España: Ceuta y Melilla}

El Mediterráneo es una zona de enormes disparidades económicas, donde la brecha nortesur está claramente definida, diferenciándose ambas riberas no solo en el plano económico, sino también en otros aspectos tan relevantes como la religión y la cultura. Todo ello conlleva que la cuenca mediterránea sea un núcleo potencial de desestabilización, tal como se ha comprobado en las últimas décadas con el incremento de la inmigración, el estallido de la primavera árabe, y el aumento del yihadismo.

La brecha económica que existía en décadas anteriores perdura en la actualidad e incluso se ha incrementado. El hambre, los conflictos interétnicos, la inseguridad ciudadana, y la carencia de un futuro seguro en los países de origen de los migrantes, son los desencadenantes de los flujos migratorios que subsisten, se acrecientan y diversifican, dejando en evidencia la falta de efectividad de la militarización de las fronteras exteriores, $\mathrm{y}$ aflorando las deficiencias en la gestión migratoria comunitaria.

En este contexto, es preciso ser consciente de la implicación que tiene el hecho de que España sea una de las fronteras sur de Europa. Ceuta y Melilla comparten una herencia histórica y un mapa jurídico peculiar que influye de modo especial en los procesos migratorios que ambas ciudades experimentan, adquiriendo en ellas el fenómeno migratorio una mayor complejidad de la que concurre en la Península Ibérica. Desde comienzos de los años noventa, Ceuta y Melilla se han convertido en una de las zonas de entrada a Europa más frecuentada por los inmigrantes clandestinos.

El año 1995 representa una línea imaginaria temporal dentro de las migraciones a través de Ceuta y Melilla, puesto que marca el comienzo de los proyectos de gestión y obstaculización migratoria.

\subsection{1. ¿Qué hace la Unión Europea frente a esta situación?}

Por una parte, blinda sus fronteras. Esta es la estrategia más antigua y la más convencional que ha utilizado Europa. Resulta evidente y terrible el tremendo coste en vidas humanas que conlleva esta medida.

En su informe 2017-18, Amnistía Internacional señala que estas políticas de negación llevan directamente a la segunda estrategia, más reciente, que es la externalización de las fronteras.

En este informe Amnistía Internacional denuncia que la Unión Europea y varios gobiernos europeos, con el italiano a la cabeza, intentaron cerrar la ruta libia cooperando con la Guardia Costera libia y otros actores presentes en el país, firmando una serie de acuerdos de cooperación con autoridades libias responsables de graves violaciones de derechos humanos, en particular la Guardia Costera y la Dirección General para la Lucha contra la Inmigración Ilegal. (Informe Amnistía Internacional, 2018: 56).

Esta estrategia de la Unión Europea es la que causa mayor controversia, puesto que roza la ilegalidad y vulnera la normativa internacional sobre Derechos Humanos. Por un lado, Europa cierra sus fronteras, aumenta su vigilancia a través del endurecimiento del Sistema Europeo de Vigilancia de Fronteras (Eurosur) y de la ampliación de competencias de Frontex (Agencia Europea para la Gestión de la Cooperación Operativa en las Fronteras Exteriores de los Estados miembros de la Unión Europea) y al mismo tiempo llega a acuerdos con terceros países, como es el caso de Marruecos, Turquía, y Libia para que realicen las labores de control migratorio que la propia UE no quiere asumir.

Esto tiene graves consecuencias: en el proyecto de la OIM sobre Migrantes Desaparecidos, podemos constatar que 7.927 migrantes murieron o desaparecieron en el mundo en 2016, y estas cifras solo se refieren a los casos de los que la OIM ha tenido 
conocimiento. También podemos constatar que el número de muertes y desapariciones de migrantes registrado en el mal Mediterráneo aumentó un 36\% en 2016. (Informe OIM: 42).

Hasta la fecha los países africanos continúan siendo emisores de emigrantes, y no parece que la situación vaya a cambiar en el futuro, por lo que los gobiernos europeos deberían plantearse otro modo de gestionar las políticas de inmigración (Bradley, 2017: 99)

Toda esta política de blindaje y militarización afecta sobremanera a las ciudades autónomas de Melilla y Ceuta, ya que las convierte en un espacio intermedio, en una tierra de nadie (son Europa, están en África, no forman parte de la zona Schengen) y en ese limbo legal actúan inevitablemente como un presidio para emigrantes.

Las decisiones en materia migratoria por parte de los países europeos han resultado ser terriblemente controvertidas y han repercutido peyorativamente en la imagen de la Unión Europea y de sus estados miembros y hasta la fecha han sido muchas las ONG's que han denunciado estos hechos alegando que se están vulnerando gravemente los derechos de las personas migrantes.

Por otro lado, parece que no se quiere tomar conciencia de que la mayoría de los inmigrantes que deciden emigrar a Europa lo hacen de la mano de alguna de las redes mafiosas de tráfico de personas que actúan en sus territorios (Maluszynski, 2017:24; Wall et al., 2015: 4).

Estas mafias han ido proliferando y enriqueciéndose a costa de aprovecharse de la necesidad de las personas que, con grave riego de su vida, tratan de buscar un futuro mejor y realizan sus labores delictivas con una facilidad sorprendente y difícilmente comprensible (McAuliffe et al., 2015: 32).

Las personas que toman la decisión de emigrar de su país, llegan a nuestras fronteras con una gran carga psicológica y un enorme cansancio físico. Meses de viaje por Mali, Argelia, Marruecos... múltiples peligros que enfrentar, miedo, frío, hambre... todo esto supone que, cuando entran a residir en un CETI (Centro de Estancia Temporal de Inmigrantes) lleguen con síntomas de ansiedad y depresión, síntomas que solo pueden empeorar puesto que les esperan meses e incluso años de trámites burocráticos y de incertidumbre (Informe CETI, 2015).

La dura espera burocrática, sin tener posibilidad de acceder a la península y moverse libremente, siendo conocedores de que en cualquier momento puede llegar una orden de expulsión, influye en el estado anímico de los inmigrantes. Además, se une el hecho de que no se les permita empadronarse en la ciudad, lo que les imposibilita poder buscar trabajo mientras esperan. Este impedimento supone que los inmigrantes, en Ceuta cuenten con menos derechos que aquellos que residen en la península, pues al no poder empadronarse no pueden acceder a la residencia legal a los tres años como permite la ley, ni tienen acceso a la sanidad ni la educación pública, según denuncia la Asociación ELIN en su informe de 2010.

La aparición de la inmigración, en el caso de España, no solo ha tenido repercusión a nivel político y económico, sino que su impacto en la sociedad también ha sido notable. La convivencia con personas de distintas razas y culturas ha convertido a los españoles en un grupo más heterogéneo y multicultural, donde los intercambios culturales y las nuevas experiencias han enriquecido a todos como personas.

No obstante, no todo el mundo ha aceptado la multiculturalidad como algo positivo, sino que a veces se ve como una amenaza a las costumbres propias. El racismo se ha incrementado de forma preocupante en nuestra sociedad, alcanzando incluso a la esfera política, donde se incrementa la presencia de partidos de índole radical, que van creciendo en votos. Se acusa al inmigrante de no haberse integrado completamente, de ser los causantes de la delincuencia, de la inseguridad ciudadana y de crear una competencia desleal en el ámbito 
laboral al aceptar trabajos por salarios irrisorios, en lugar de cuestionar la falta de voluntad política para ofrecer una solución a los problemas de exclusión social, precariedad laboral y desigualdades que las personas inmigrantes afrontan cuando llegan a nuestros países (Fernández, 2017: 65).

Esta situación se ha visto acentuada en los últimos años debido a la crisis económica (Font, 2017; Font, Llorens y Moncada, 2017: 1-2).

La ausencia de una política común europea y el evidente desinterés por parte de ciertos países europeos en solventar el problema de la migración denota una total falta de empatía hacia el fenómeno migratorio que se considera un problema de los países que conforman la frontera exterior europea, especialmente aquellos que se ubican en el sur, como son, España, Grecia, Italia y Portugal. Se entiende desde las instituciones europeas que la donación de financiación para militarizar dichas fronteras es una medida suficiente, gracias a la cual se puede exigir a los países de la ribera norte mediterránea máxima diligencia en la supresión de las entradas ilegales a la zona Schengen pero esta situación no se resolverá hasta que no admitamos que la inmigración no es una cuestión que deba ser abordada únicamente desde criterios económicos, sino que se trata de una cuestión social en la que debería primar el más absoluto respeto a las normas internacionales de Derechos Humanos, aplicables a todas las personas, sean o no migrantes, al tiempo que debe entenderse que es una cuestión que afecta a todos los Estados miembros de Europa, no solo a los que forman parte de su frontera sur.

Es evidente que el modelo de gestión migratorio a través del cual se opera en la actualidad no está siendo efectivo, debido en parte a que basa sus medidas en estrategias parciales, cortoplacistas y que suponen la negación del problema real. La militarización de la frontera exterior de la Unión Europea, los acuerdos bilaterales con Marruecos, Turquía y Libia para externalizar las fronteras, o los acuerdos puntuales de repatriación con otros países, no han logrado minorar la presión migratoria en nuestras fronteras.

Se necesita una redefinición de las políticas de inmigración, la enumeración y análisis de sus diversas modalidades, la concienciación europea de que nos enfrentamos a un problema global, y bajo estos parámetros la creación de una política común a nivel europeo que centre su voluntad en colaborar para solucionar los problemas en origen. La modificación del modelo de gestión migratoria se convierte en una necesidad perentoria y evidente. Esta modificación debería centrar su principal esfuerzo en conseguir una mayor coordinación a nivel europeo para la creación de una política común en materia migratoria. Solo de este modo, atendiendo al fenómeno desde una perspectiva global, se podrán definir los hitos principales que deban perfilar dicho modelo de gestión (Czaika et al., 2014: 290).

\section{RIESGOS PSICOSOCIALES ASOCIADOS A LA INSERCIÓN LABORAL DE LA POBLACIÓN MIGRANTE. SÍNDROME DE ULISES.}

El contexto actual de grave crisis económica ha añadido nuevas y dolorosas adversidades a los inmigrantes, incrementando las dificultades de elaboración del duelo migratorio.

La previsión de la ONU es que el número de emigrantes se duplicará en los próximos veinte años, constituyendo lo que se denomina ya el sexto continente: el continente móvil (McAuliffe et al., 2017: 27).

Es evidente que las personas que migran tienen una mayor probabilidad de padecer desempleo y la pobreza, porque tienen menos derechos acumulados en la sociedad de acogida y sufren una mayor vulnerabilidad laboral y más posibilidades de exclusión social pero no por ello dejan de ser ciudadanos, vecinos, compañeros, seres humanos que formar 
parte de nuestra realidad social. Aunque pueda parecer muy evidente, resulta muy importante poner esto en valor, sobre todo en el contexto económico actual, en el que resulta tan frecuente encontrar imágenes estereotipadas sobre el fenómeno migratorio especialmente relacionadas con aspectos laborales y económicos, que no tienen en cuenta el enriquecimiento cultural y social que este proceso supone.

Es necesario superar estos estereotipos para poder descubrir que cada migrante es una persona que ha dejado su tierra, su cultura, su familia... (Clemente et al., 2013: 85) simplemente poniendo en práctica el artículo 13 de la Declaración Universal de Derechos Humanos que recoge el derecho de todas las personas a circular libremente y a elegir su residencia en el territorio de un estado, así como a salir de cualquier país incluso del propio y a regresar a él.

Cabe resaltar en este punto, en este año en el que celebramos el 70 aniversario de la Declaración Universal de Derechos Humanos, que todavía queda mucho por hacer y estamos muy lejos de poder dar por sentado su contenido.

Emigrar se está convirtiendo hoy en día para millones de personas en un proceso que posee unos niveles de estrés tan intensos que llega a superar la capacidad de adaptación de los seres humanos. Estas personas sufren el riesgo de padecer el síndrome del inmigrante con estrés crónico y múltiple o síndrome de Ulises, debido a que existe una gran deshumanización al abordar las migraciones, ya que se presta muy poca atención a los sentimientos y a las vivencias de los protagonistas de la migración (Achotegui, 2012).

Debemos recalcar que el proceso de adaptación inherente a toda migración no depende en exclusiva de las estrategias y recursos de las que el migrante pueda disponer, sino que tiene mucho que ver con las actitudes de la población de acogida que el migrante encuentre a su llegada.

Este proceso de aculturación, que se da de forma natural cuando entran en contacto dos referentes culturales diferentes, puede implicar cambios en ambas culturas. Pero generalmente uno de los dos referentes impera y domina sobre el otro. El efecto derivado de dicha situación se conoce como estrés aculturativo.

La aculturación es un proceso dinámico que incluye múltiples aspectos, mediante los cuales los individuos se ajustan gradualmente al nuevo entorno. La aculturación es un proceso de afrontamiento y ajuste que incluye estrategias que utiliza el individuo para vivir entre dos culturas siendo unas más adaptativas que otras. Incluye también un cambio gradual en distintas áreas que afectan al individuo: lenguaje, ajustes en procesos cognitivos como la percepción, estilos de comunicación, formas de relación interpersonal, valores, identidad, actitudes y estrés de aculturación (Vallejo y Moreno, 2014: 53-67).

Berry et al. (2002) agrupan las estrategias de aculturación en dos dimensiones, basadas en la orientación hacia uno de los grupos culturales: una es la preferencia por mantener la propia identidad y herencia cultural; y la segunda es la tendencia a tener un mayor contacto con el grupo mayoritario (la sociedad receptora). Dependiendo del grado de contacto con los dos grupos se distinguen las siguientes estrategias: asimilación, integración, separación y marginalización.

Dada la importancia del fenómeno migratorio, en las últimas décadas se han venido realizando algunas investigaciones empíricas destinadas a conocer los efectos del cambio cultural, a partir de las cuales se han definido conceptos como estrés de aculturación, ajuste y shock intercultural, identidad étnica y otros para referirse a las reacciones de los individuos ante el cambio (Elorriaga, Ibabe y Arnoso, 2014: 382-385). 


\subsection{Duelo migratorio}

Desde la perspectiva psicológica se considera que la migración es un acontecimiento de la vida que, como cualquier cambio, supone una parte de estrés, de tensión, a la que se denomina duelo migratorio. Podemos definir el estrés como un desequilibrio sustancial entre las demandas ambientales percibidas y las capacidades de respuesta del sujeto y definimos el duelo como el proceso de reorganización de la personalidad que tiene lugar cuando se pierde algo significativo para el sujeto (Lazarus, 2000).

Hay una clara correlación entre ellos, que se hace evidente en la aparición del Síndrome de Ulises, esto es, cuando las vivencias a las que se ven sometidas las personas superan sus propias capacidades de adaptación, haciendo del todo imposible la elaboración del duelo (Achotegui, 2012).

El Síndrome del inmigrante con estrés crónico y múltiple hace referencia al estrés como su elemento fundamental. Aunque el Síndrome de Ulises posee un diagnóstico diferencial del estrés, se define como el cuadro reactivo de estrés con características concretas, que lo convierten en crónico y múltiple ante las dificultades del hecho migratorio.

Las personas disponemos de capacidades para migrar y elaborar el proceso del proyecto migratorio, así como el duelo que conlleva. Pero el estrés o el duelo migratorio no pueden compararse con otro tipo de estrés, ya que puede ser un factor de riesgo si se dan las siguientes situaciones:

a. Si existe vulnerabilidad en la persona inmigrante antes de migrar.

b. Si el nivel de estresores es muy alto porque su medio de acogida es hostil.

c. Si se dan ambas condiciones.

Migrar no significa quedar reducido al duelo migratorio, ya que en el proceso migratorio se manifiestan también beneficios que no deben quedar olvidado pero el duelo migratorio se define por las características específicas que lo diferencian de otros (Achotegui, 2012):

1) Es un duelo parcial, ya que el país de origen (el objeto de la pérdida) no desaparece y cabe la posibilidad de contactar con él (teléfono, internet).

2) Es un duelo recurrente que provoca un ir y venir emocional al país de origen, reavivando vínculos que entorpecen la elaboración de la separación.

3) Es un duelo vinculado a aspectos infantiles arraigados, condicionado entonces por todo lo vivido en la infancia, base de la estructura de la personalidad.

4) Es un duelo múltiple, en el que todo alrededor de la persona cambia

5) Es un duelo que afecta a la identidad, en cuanto se dan profundos cambios en la personalidad del inmigrante. Elaborar el duelo migratorio en su multiplicidad (la tierra, el estatus social, la cultura, la lengua,) produce cambios en el sujeto. Cambios que pueden desarrollarse en una persona madura, sana o que, por el contrario, pueden desestructurar su psicología.

6) Es un duelo que conlleva una regresión psicológica, ya que tantos cambios producen actitudes de inseguridad que derivan en conductas más infantiles, de falta de autonomía, de dependencia ante figuras de autoridad, de queja infantil o "pataleta" ante el dolor y la frustración, de sobrevaloración de los líderes o jerarquización

7) Es un duelo que tiene lugar en determinadas etapas, relacionadas con la elaboración psicológica del proceso del duelo negación ante la realidad del cambio, resistencia ante las dificultades que supone la adaptación, aceptación de la nueva situación en el país de acogida y restitución, reconciliación afectiva con el país de origen y el país de acogida.

8) Es un duelo cuya elaboración utiliza defensas psicológicas y errores en el procesamiento de la información.

9) Es un duelo con sentimientos de ambivalencia hacia el país de origen y el país de 
acogida, ya que las emociones de amor y rabia se combinan con los vínculos originarios y el proceso de adaptación al nuevo país.

10) Es un duelo que también afecta a los autóctonos y a los que se quedan en el país de origen. El ser humano es un ser social por naturaleza, de modo que todos sus cambios afectan a su red social, tienen un efecto en la dinámica de pareja y familia. Las repercusiones conjuntas, de uno y otro lado no quedan aisladas en la persona concreta, sino que se ramifica en la sociedad.

11) Es un duelo migratorio transgeneracional, ya que continúa en sus hijos y podría extenderse a generaciones posteriores si no se convierten en ciudadanos de pleno derecho en la sociedad de acogida.

El segundo duelo migratorio, en el que el regreso del inmigrante a su país se vive como nueva migración. Los cambios personales producidos fuera del país de origen durante el tiempo de la migración, la falta de cumplimiento de las expectativas económicas de los familiares y amigos y el sentimiento de vergüenza asociado al fracaso, desembocan en la llegada de una persona distinta a un país distinto, con lo que eso supone de readaptación constante

En el Informe sobre las Migraciones en el Mundo 2018, se hace referencia a este efecto negativo que supone el retorno en la vida del emigrante, señalando además el incremento significativo que se ha producido en el número de retornos en los últimos años (Informe 2018: 29).

El duelo migratorio se compone de siete elementos: la familia, la lengua, la cultura, la tierra, el estatus social, el grupo de pertenencia y los riesgos físicos.

Estos elementos forman parte en mayor o menor medida de todos los procesos migratorios (Achotegui, 2012):

a) La familia y los amigos: comprende la separación de la familia y amigos, la pérdida de la red familiar y de los vínculos infantiles. En el ámbito personal supone la separación de hijos pequeños, separación de pareja traumática, reagrupación familiar traumática...En el ámbito social supone no poder enviar nada de dinero a su familia, en otros ámbitos supone el peligro para sus familiares en el país de origen: guerras, amenazas de mafias...

b) La lengua: la pérdida de contacto con la lengua materna para el uso cotidiano hace difícil la expresión de los aspectos íntimos. Además, el esfuerzo que supone aprender y adaptarse a la nueva lengua del país de acogida, implica un tiempo del que el inmigrante no dispone para comenzar a relacionarse y comunicarse. En el ámbito personal esto supone no tener relación con los autóctonos. En el ámbito social supone no tener acceso a los recursos para el aprendizaje de la lengua.

c) La cultura: la pérdida de valores, hábitos, costumbres, religión y formas de vida propios de la cultura de procedencia. En el ámbito personal implica no tener relaciones con los autóctonos para poder contactar con la cultura de acogida. En el ámbito social implica no tener acceso a los recursos para la integración en la cultura del país de acogida.

d) La tierra: la pérdida del paisaje, olores, luz, colores de la tierra conllevan desubicación cuando, por ejemplo, se migra a un país con un clima extremadamente frío y oscuro.

e) El estatus social: la pérdida del nivel social en origen sitúa al inmigrante en el último escalafón social, del que dependen sus papeles, trabajo, vivienda y la posibilidad de ascenso social. En el ámbito personal implica la existencia de dificultades extremas con los familiares por temas de vivienda, trabajo... En el ámbito social implica no poder enviar nada de dinero a su familia En otros ámbitos implica la existencia de un peligro de ruina total para sus familiares en el país de origen: guerras, amenazas de mafias... 
f) El contacto con el grupo étnico. La pérdida del grupo de referencia donde nos identifican y reconocen conlleva inseguridades y temores. En el ámbito personal esto conlleva conflictos familiares graves, malos tratos, por razones culturales. En el ámbito social supone ser víctima de agresiones racistas.

g) Los riesgos para la integración física. Los viajes peligrosos, la indefensión y el riesgo de expulsión suponen la pérdida de la seguridad, una de las necesidades básicas del ser humano. En el ámbito personal supone la existencia de riesgos extremos en la familia: malos tratos, abusos, desahucios. En el ámbito social implica la existencia de riesgos extremos en el ámbito laboral, economía sumergida, etc. En otros ámbitos supone el grave peligro para sus familiares en el país de origen: guerras, amenazas de mafias...

La migración posee una serie de ventajas y beneficios como puedan ser el acceso a nuevas oportunidades y horizontes, pero también un conjunto de dificultades, de tensiones, de situaciones de esfuerzo, y tiene una parte problemática a la que se denomina estrés o duelo migratorio. No podemos relacionar la migración únicamente con el duelo migratorio, puesto que esto supondría negar la existencia de los aspectos positivos de la migración: la migración es muchas veces una solución, más que un problema; pero no deja de ser una solución que encierra en sí misma un problema.

El duelo migratorio es un duelo complejo y muy difícil de superar, sobre todo si las circunstancias personales y sociales del inmigrante son problemáticas hasta el punto de que pueden llegar a desestructurar al sujeto. Según Achotegui (2012) se deben diferenciar tres tipos de duelos desde la perspectiva de su intensidad: el duelo simple, el duelo complicado y el duelo extremo:

1) Simples: son dificultades leves del medio que no impiden la elaboración del duelo migratorio.

2) Complicados: son dificultades relevantes del medio que con esfuerzo pueden permitir la elaboración del duelo migratorio.

3) Extremos: limitaciones muy graves del medio que impiden la elaboración del duelo migratorio.

Destaca también Achotegui los principales estresores a tener en cuenta en este proceso:

a) la separación forzada de los seres queridos que supone una ruptura del instinto del apego

b) el sentimiento de desesperanza por el fracaso del proyecto migratorio y la ausencia de oportunidades

c) la lucha por la supervivencia

d) el miedo, el terror que se vive en los viajes migratorios.

Estos estresores de tanta relevancia y que van más allá del clásico estrés aculturativo, se hayan potenciados por toda una serie de factores, tales como: la multiplicidad, la cronicidad, la intensidad y la relevancia de los estresores, la ausencia de sensación de control y los fuertes déficits en sus redes de apoyo social.

Esta combinación de soledad, fracaso en el logro de los objetivos, vivencia de carencias extremas, y terror, crea la base psicológica y psicosocial del síndrome del inmigrante con estrés crónico y múltiple (Síndrome de Ulises).

Podemos por tanto definir el Síndrome de Ulises no como una enfermedad, puesto que no lo es, sino como un cuadro reactivo de estrés ante situaciones de duelo migratorio extremo que no puede ser elaborado por las características específicas ya tratadas, aunque esta situación si puede llegar a ser la base sobre la que se desarrollen enfermedades mentales 
graves posteriores.

Los seres humanos poseemos capacidad para emigrar y procesar el duelo. Descendemos de seres que han emigrado con éxito muchas veces a lo largo del proceso evolutivo, por lo que no podemos considerar la emigración en sí misma como una causa de trastorno mental, sino tan solo como un factor de riesgo en el caso de que exista vulnerabilidad, es decir, si el inmigrante no está sano o padece discapacidades; y si el nivel de estresores es muy alto por ejemplo cuando el medio de acogida es muy hostil; o si se producen ambas cuestiones (Ventevogel et al., 2015: 6).

Aunque la migración es un fenómeno tan antiguo como la humanidad, cada migración posee sus características específicas y las migraciones del siglo XXI se están realizando en condiciones especialmente difíciles, porque emigrar nunca ha sido fácil, pero no es lo mismo emigrar en condiciones difíciles que hacerlo en condiciones extremas. Más de seis millones de españoles emigraron en el siglo XX, el $80 \%$ a América. No podemos ni debemos olvidar que no sólo España ha sido un país de emigrantes, sino que toda Europa ha sido un continente de emigrantes: se calcula que entre el siglo XVIII y XIX setenta millones de europeos emigraron a América (Delgado-Rodríguez, 2014: 671).

La denominación "síndrome de Ulises" es muy importante puesto que contribuye a evitar que estos inmigrantes, por no existir un concepto para su problemática, sean víctimas de la desvalorización de sus padecimientos y del peligro de ser incorrectamente diagnosticados como depresivos o con trastornos adaptativos.

La vivencia tan prolongada de situaciones de estrés tan intensas afecta profundamente a la personalidad, dando lugar a una amplia sintomatología: depresión, ansiedad, somatizaciones, confusiones, etc., como en el episodio de la Odisea en el que Ulises le dice a Polifemo que su nombre es Nadie (Achotegui, 2012).

\section{CONCLUSIONES}

El drama de las personas refugiadas que huyen de conflictos armados y que, ante la falta de vías legales y seguras para obtener protección, arriesgan su vida en el Mediterráneo, ha conmovido de forma momentánea la conciencia de la sociedad europea. Pero la reacción de los Estados miembros y de las instituciones comunitarias está poniendo de manifiesto la crisis de valores en la que está sumida la Unión Europea, incapaz de articular medidas inspiradas en sus principios fundacionales de solidaridad y respeto a los Derechos Humanos que pongan fin a esta situación.

Emigrar se está convirtiendo hoy para millones de personas en un proceso que genera unos niveles de estrés tan intensos que llega a superar la capacidad de adaptación de los seres humanos, siendo estas personas potenciales candidatos a padecer el síndrome de Ulises. El conjunto de síntomas que conforman este síndrome constituye un problema de salud mental emergente en los países de acogida de los inmigrantes.

Por este motivo resulta urgente y necesaria la redefinición de las políticas de inmigración, la enumeración y análisis de sus diversas modalidades, la concienciación europea de que nos enfrentamos a un problema global y, bajo estos parámetros, la creación de una política común a nivel europeo que centre su voluntad en colaborar para solucionar los problemas en origen y afrontar los movimientos migratorios que estos problemas causan. La modificación del modelo de gestión migratoria se convierte en una necesidad perentoria y evidente. Esta modificación debería centrar su principal esfuerzo en conseguir una mayor coordinación a nivel europeo para la creación de una política común en materia migratoria. Solo de este 
modo, atendiendo al fenómeno desde una perspectiva global, se podrán definir los hitos principales que deban perfilar dicho modelo de gestión.

Esta propuesta para una nueva definición de las políticas de acogida e integración de la población migrante debe atajar cuanto antes la exclusión social, la desigualdad y la precariedad, que se ven favorecidas por los factores estructurales, jurídicos, económicos y sociales que caracterizan nuestras sociedades y no pueden de ningún modo ser achacados únicamente a las condiciones, capacidades y competencias individuales de las personas migrantes.

A lo largo de la historia todas las sociedades han ejercido prácticas solidarias, pero a cada época le corresponde un tipo concreto de solidaridad fruto de la coyuntura histórica, y es crucial que en este momento nuestra sociedad trate por todos los medios de evitar el asistencialismo en la respuesta al tiempo que tratemos de articular respuestas conjuntas y coordinadas, no solo desde las administraciones públicas, sino también desde las organizaciones sociales y desde la totalidad de la ciudadanía comprometida.

La creciente multiculturalidad tan relacionada con todos los procesos globales en que nos vemos inmersos comunica directamente con el proceso migratorio, tanto desde el mundo de la salud como desde otros ámbitos igual de importantes como son el ámbito educativo o el laboral, que hacen necesaria una revisión integral de las políticas y programas de acogida enfocados en todo momento desde la perspectiva de la justicia social; puesto que resulta incompatible la construcción de una sociedad mínimamente estable sin afrontar correctamente el fenómeno migratorio.

Por esto es tan importante el trabajo de sensibilización sobre qué es el desplazamiento forzado en el mundo, su origen, sus causas, y su dimensión, siendo especialmente importante el trabajo de sensibilización referido específicamente a colectivos de funcionarios y trabajadores públicos de servicios sociales, sanitarios, educativos, judiciales, laborales puesto que ellos son una pieza clave de la correcta integración que se brinde a la población migrante en nuestra sociedad.

\section{BIBLIOGRAFÍA}

Achotegui, J. (2012) "La crisis como factor agravante del Síndrome de Ulises”. Temas de psicoanálisis, 3: $1-16$.

Achotegui, J. (2009) "Migración y salud mental. El síndrome del inmigrante con estrés crónico y múltiple (síndrome de Ulises)". Zerbitzuan, 46: 163-171.

Achotegui, J.; Llopis, A.; Morales, M. y Espeso, D. (2012) "Cefaleas en inmigrantes. Estudio de 1.043 casos. Análisis comparativo entre cefaleas en inmigrantes con Síndrome de Ulises y otros diagnósticos". Revista Norte de Salud Mental, 10 (44): 34-42.

Adepoju, A. (2016) "Migration Dynamics, Refugees and Internally Displaced Persons in Africa". Iniciativa Impacto Académico de las Naciones Unidas (UNAI), en https://academicimpact.un.org/content/migration-dynamics-refugees-and-internally-displacedpersons-africa

Álvarez, P.; Briod, P.; Ferrari, O. y Rieder, U. (2015) "Remittances: How reliable are the data?" Migration Policy Practice, 5(2): 42-46.

Amnistía Internacional (2018) Informe 2017-18 Amnistía Internacional. La situación de los derechos humanos en el mundo. Londres: Amnistía Internacional.

Asociación Elin (2010) Ceuta. El drama silenciado de una frontera. Informe sobre la realidad de la inmigración en Ceuta hoy, en http://www.asociacionelin.com/wpcontent/uploads/2017/08/informeelin-ceuta.pdf 
Asociación Pro Derechos Humanos de Andalucía (2018) Derechos humanos en la frontera sur. Sevilla: APDHA, en https://www.apdha.org/media/informe-frontera-sur-2018-web.pdf

Basabe, N.; Zlobira, A. y Páez, D (2004) Integración socio- cultural y adaptación psicológica de los inmigrantes extranjeros en el País Vasco. Vitoria-Gasteiz: Servicio central de publicaciones del Gobierno Vasco.

Bennett, C. J. (2016) "Voter databases, micro-targeting, and data protection law: can political parties campaign in Europe as they do in North America?" International Data Privacy Law, 6(4): 261-275, DOI: https://doi.org/10.1093/idpl/ipw021

Berry, J.W.; Kim, U.; Minde, T. y Muk, D. (1987) “Comparative studies of acculturative stress". International Migration Review, 21(3): 491-511, DOI: 10.2307/2546607

Berry, J.W.; Portinga, Y.H.; Segal, M. y Dasen P. (2002) Cross-cultural psychology. United Kingdom: Cambridge University Press UK.

Billiet, J.B. (1995) "Church involvement, individualism, and ethnic prejudice among Flemish Roman Catholics: new evidence of a moderating effect". Journal of the Scientific Study of Religion, 34 (2): 224-233, DOI: 10.2307/1386767

Black, J.; Mendenhall, M. y Oddou, G. (1991) "Toward a comprenhensive models international adjustment. An interaction of multiple theoretical perspectives". Academy of management review, 16 (2): 291-317.

Blinder, S. (2015) "Imagined immigration: The impact of different meanings of 'immigrants' in public opinion and policy debates in Britain". Political Studies, 80-100, DOI: https://doi.org/10.1111/1467-9248.12053

Bochner, S. (1994) "Cross-cultural differences in the self-concept: a test of Hofstede individualismcollectivism distinction". Journal of Cross-Cultural Psychology, 25 (2): 273-283, DOI: https://doi.org/10.1177/0022022194252007

Bradley, M. (2017) "The International Organization for Migration (IOM): Gaining power in the forced migration regime". Refuge, 97-106.

Cebrian, J.A.; Bodega, M.I.; Martin-Lou, M. A. y Guajardo, F. (2010) "La crisis económica internacional y sus repercusiones en España y en su población inmigrante". Estudios Geográficos, 72 (268): 67-101, DOI: 10.3989/estgeogr.0505

Centelles García, C.F. (2015) "Actitudes hacia la inmigración en Europa: análisis comparativo entre países sobre la tolerancia a los inmigrantes". Praxis Sociológica, 19: 41-58.

Ceobanu, A.M. y Escandell, X. (2010) "Comparative analysis of public attitudes toward immigrants and immigration Using multinational survey data: a review of theories and research". Annual Review of Sociology, 36: 309-328, DOI: https://doi.org/10.1146/annurev.soc.012809.102651

CETI (2015) “Memoria del CETI 2014". Ceuta, 1-38, en http://blog.uclm.es/ceti/files/2015/07/Memo ria-CETI_199-2014.pdf

Church, A.T. (1982) "Sojourner adjustment". Psychology Bulletin, 91 (3): 540-572, DOI: http://dx.doi.org/10.1037/0033-2909.91.3.540

Citrin, J. y Sides, J. (2008) "Immigration and the imagined community in Europe and the United States". Political Studies, 56: 33-56, DOI:https://doi.org/10.1111/j.1467-9248.2007.00716.x

Clemente, M., Espinosa, P. y Fernández, M. (2013) "La integración de los inmigrantes a través de la comunicación". Barataria. Revista Castellano-Manchega de Ciencias Sociales, 16: 83-96, DOI: http://dx.doi.org/10.20932/barataria.v0i16.73

Comisión Española de Ayuda al Refugiado (CEAR) (2018) Informe 2018: Las personas refugiadas en España y Europa. Madrid: Cear.

Comisión Española de Ayuda al Refugiado (CEAR) (2017) Informe 2016: Las personas refugiadas en España y Europa. Madrid: Cear.

Comisión Española de Ayuda al Refugiado (CEAR) (2016) Informe sobre la discriminación de personas migrantes y refugiadas en España. Madrid: Cear.

Czaika, M. y H. de Haas (2014) "The globalization of migration: Has the world become more migratory?" International Migration Review, 283-323, DOI: https://doi.org/10.1111/imre.12095

Delgado-Rodríguez, M. (2014) "Inmigration and health in Spain". Revista Española de Salud Pública, 88 (6): 671-674, DOI: http://dx.doi.org/10.4321/S1135-57272014000600001 
Elgorriaga, E.; Izaskun, I. y Arnoso, A. (2014) "Psychosocial adjustment of Spanish emigrants and nonemigrants". Social and Behavioral Sciences, 131: 382-385, DOI: 10.1016/j.sbspro.2014.04.134

Felt, E.; Ronda, E.; Casabona, J.; Hernando, C. y Ferrer, L. (2015) "Informing policies and programs to support inmigrant health in Spain". Ciber-Esp, 1-28.

Fernández, M.B (2017) "Los inmigrantes ante el mercado laboral español en tiempos de crisis". Barataria. Revista Castellano-Manchega de Ciencias Sociales, 23: 53-70, DOI: https://doi.org/10.20932/barataria.v0i23.351

Flahaux, M. L. y H. de Haas (2016) "African migration: Trends, patterns, drivers". Comparative Migration Studies, 1-25, DOI: https://doi.org/10.1186/s40878-015-0015-6

Font, A. (2017) "Desigualdad e inmigración: su reflejo en la salud laboral". Dossier: inmigración y salud laboral, 1-2

Font, A.; Llorens. C. y Moncada, S. (2017) "Un plus de riesgos psicosociales. Prácticas empresariales insalubres y discriminación". Dossier: inmigración y salud laboral, 1-2

Furnham, A. y Bochner, S. (1986) "Culture shock. Psychological reactions to unfamiliar environments". Londres: Methuen \& Co.Ltd.

Hall, M. (2017) "Psychological well-being of refugees throught the relocation process". Applied Psychology OPUS, 1-7.

Hammer, H.R. (1989) Intercultural communication competence. Handbook of international and intercultural communication. Los Angeles: Sage Publications.

Instituto Nacional de Estadística INE (2018) "España en cifras", 1-60, en https://www.ine.es/prodyser/ espa_cifras/2018/files/assets/common/downloads/publication.pdf?uni $=4 \mathrm{f} 7 \mathrm{e} 7 \mathrm{~b} 429 \mathrm{c} 56 \mathrm{ccbc} 4 \mathrm{bf56b} 3 \mathrm{e}$ $93 \mathrm{ebc} 47 \mathrm{~b}$

Igartua, J.J.; Humanes, M.L.; Muñiz, C.; Cheng, L.; Mellado, C.; Medina, E. y Erazo, M.A. (2004) "Tratamiento informativo de la inmigración de la prensa española y opinión pública". Comunicación presentada en el VII congreso latinoamericano de investigadores de la comunicación, 1-15.

Igartua, J.J.; Muñiz, C. y Otero. J.A. (2005) "El tratamiento informativo de la inmigración en prensa y la televisión española. Una aproximación empírica desde la teoría del framing”. Global Media Journal, 3 (5): 1-15, en http://www.redalyc.org/articulo.oa?id=68730501

Igartua, J.J.; Muñiz, C. y Cheng, L. (2005) "La inmigración en la prensa española. Aportaciones empíricas y metodologías desde la teoría del encuadre noticioso". Migraciones, 17:1-39, DOI: http://revistas.upcomillas.es/index.php/revistamigraciones/article/view/4220

Kealey, D. (1996) The challenge of international personnel selection. Handbook of intercultural training. London: Sage Publications.

Kim, Y.Y. (1991) "Intercultural communication competence. A systems theoric view". Cross-cultural interpersonal communication, 1-13.

Konle-Seidl, R. y Bolits, G. (2016) "Labour market integration of refugees: strategies and good practices". Policy Department A: economic and scientific policy. European Parliament, 1-58, en http://www.europarl.europa.eu/RegData/etudes/STUD/2016/578956/IPOL_STU(2016)578956_EN. pdf

Laczko, F. (2017) “Improving data on migration: A 10-point plan”. Migration Policy Practice, 1-7.

Lazarus, R. (2000) Estrés y emoción. Manejo e implicaciones en nuestra salud. Bilbao: Desclée de Bouvier.

Martin, S. (2016) "New models of international agreement for refugee protection". Journal on Migration and Human Security, 60-75, DOI: https://doi.org/10.14240/jmhs.v4i3.62

Martínez, V. (2017) "Libertad de expresión y seguridad: un análisis del discurso periodístico sobre inmigración". Barataria. Revista castellano-manchega de ciencias sociales, 23: 87-102, DOI: https://doi.org/10.20932/barataria.v0i23.349

McAuliffe, M. y K. Koser (2015) "Unintended Consequences: How Migrant Smugglers are Exploiting the International Protection System", Advance, 30-33.

McAuliffe, M. y V. Mence (2017) "Irregular maritime migration as a global phenomenon". A Long Way to Go: Irregular Migration Patterns, Processes, Drivers and Decision Making. Canberra: Australian National University. 
Maluszynski, C. (2017) "Migrants, refugees and asylum seekers: vulnerable people at Europe's doorstep". Annual Report MSF, 1-9, en http://docplayer.net/25355558-Migrants-refugees-andasylum-seekers-vulnerable-people-at-europe-s-doorstep.html

Mendenhall, M. (1996) The foreign teaching assistant as expatriate manager. Handbook of intercultural training. London: Sage Publications.

Moghddam, F.M.; Taylor, D. y Wright, S. (1993) "Social psychology in cross-cultural perspective". London: Sage Publications.

Oiarzábal, P. J. y Reips, U.D. (2012) "Migration and diaspora in the age of information and communication technologies". Journal of Ethnic and Migration Studies, 1333-1338, DOI: https://doi.org/10.1080/1369183X.2012.698202

OIM (2018) "Informe de la Organización internacional para las migraciones. Informe sobre las migraciones en el mundo en 2018". Oficina de migración de la ONU, en https://publications.iom. int/system/files/pdf/wmr_2018_sp.pdf

OIM (2015) "Informe de la Organización internacional para las migraciones. Informe sobre las Migraciones en el Mundo 2015: Los migrantes y las ciudades: Nuevas colaboraciones para gestionar la movilidad". Oficina de migración de la ONU, en http://publications.iom.int/system/ files/wmr2015_sp.pdf

OIM (2013) "Informe de la Organización internacional para las migraciones. Informe sobre las Migraciones en el Mundo 2013: El bienestar de los migrantes y el desarrollo". Oficina de migración de la ONU, en http://publications.iom.int/system/files/pdf/wmr2013_sp.pdf

OIT (2017) "Informe de la Organización Internacional del Trabajo. Informe Mundial sobre Salarios 2016/2017. Desigualdades salariales en el lugar de trabajo". Oficina Internacional del Trabajo, 1140, en https://www.ilo.org/global/research/global-reports/global-wage-report/2016/lang--es/index. $\mathrm{htm}$

OIT (2016) "Informe de la Organización Internacional del Trabajo. Promover una migración equitativa". Oficina Internacional del Trabajo, en https:/www.ilo.org/wcmsp5/groups/public/--ed_norm/relconf/documents/meetingdocument/wcms_453896.pdf

Operario, D. y Fiske, S. (1999) "Integrating social identity and social cognition: a framework for bridging diverse perspectives". In D. Abrams \& M.A. Hogg (Eds.). Social identity and social cognition. Cambridge: Blackwell, pp.26-54

Paez, D.; Fernandez, I.; Ubillos, S. y Zubieta, E. (2004) Psicología social, cultura y educación. España: Pearson Educación.

Perse, E.M. (2001) Media effects and society. Oxford: Taylor \& Francis.

Rathod, J.M. (2016) "Danger and dignity: Inmigrant day laborers and occupational risk". Seton Hall Law Review, 46 (3): 813-882, DOI: https://scholarship.shu.edu/shlr/vol46/iss3/3

Rodríguez-Planas, N. y Nollenberger, N. (2016) "Labor market integration of new inmigrants in Spain". Journal of Labor Policy, 1-15, DOI: https://doi.org/10.1186/s40173-016-0062-0

Ronda-Pérez, E.; Agudelo-Suárez, A.A.; López-Jacob, M.J.; García, A. y Benavides, F. (2014) "Condiciones de trabajo y salud de los trabajadores inmigrantes en España. Revisión bibliográfica". Revista Española de Salud Pública, 88 (6): 703-714, DOI: http://dx.doi.org/10.4321/S113557272014000600004

Ruben, B.D. y Kealey, D.J. (1979) "Behavioral assessment of communication competency and the prediction of cross cultural adaptation". International journal of intercultural relations, 15-47, DOI: https://doi.org/10.1016/0147-1767(79)90045-2

Seminov, M.; Rejman, R. y Gordzosky, A. (2006) "The rise of anti-foreigner sentiment in European societies 1988-2000", American Sociological Review, 71 (3): 426-449

Sodowsky, G.R.; Lai, E.W.M. y Plake, B.S. (1991) "Moderating effects of sociocultural variables on acculturation attitudes of Hispanics and Asian Americans". Journal of counseling and development, 70: 194-204, DOI: https://doi.org/10.1002/j.1556-6676.1991.tb01583.x

Soriano Ayala, E. y Dalouh, R. (2014) "Moroccan inmigrant women in Spain: problems of identity and emotional well-being". Social and Behavioral Sciences, 222-228, DOI: 10.1016/j.sbspro.2014.04.302

Sousa, E.; Agudelo-Suárez, A.; Benavides, F.; Schenker, M.; García, A.; Benach, J. y Porthé, V. (2017) 
"Inmigration, work and health in Spain: the influence of legal status and employment contract on reported health indicators". International Journal of Public Health, 55 (5): 443-451, DOI: 10.1007/s00038-010-0141-8

Spitzberg, B.H. y Cupach, W.R. (1984) Interpersonal communication competence. London: Sage Publications.

Tajfel, H. (1978) Differentiation between social groups: studies in the psychology of intergroup relations. Cambridge: Academic Press.

Torá, I.; Martínez, J.M.; Benavides, F.; Leveque, K. y Ronda, E. (2015) "Effect of economic recession on psychosocial working conditions by workers' nationality". International Journal of Occupational and Environmental Health, 21 (4): 328-332, DOI: https://doi.org/10.1080/10773525. 2015.1122369

Vallejo, M. y Moreno, P. (2014) "Del culturalismo al bienestar psicológico. Propuesta de un modelo de satisfacción vital en el proceso de aculturación de inmigrantes". Boletin de Psicología, 110: 53-67.

Van Klingeren, M.; Boomgaarden, H.G.; Vliegenthart, R. y de Vreese, C.H. (2015) "Real world is not enough: The media as an additional source of negative attitudes toward immigration, comparing Denmark and the Netherlands". European Sociological Review, 268-283, DOI: 10.1093/esr/jcu089

Ventevogel, P.; Schinina, G.; Strang, A.; Gagliato, M. y Hansen J. (2015) "Mental health and psychosocial support for refugees, asylum-seekers and migrants on the move in Europe". Multiagency guidance note, 1-7, en http://pscentre.org/wp-content/uploads/MHPSS-Guidance-noteFINAL-12-2015.pdf

Wall, M.; Campbell, M.O. y Janbek, D. (2015) “Syrian refugees and information precarity”. New Media \& Society, 240-254, DOI: https://doi.org/10.1177/1461444815591967

Ward, C.; Bochner, S. y Furnham, A. (2001) The psychology of culture shock. Oxford: Routledge Press.

\section{Breve currículo:}

\section{Adela Reig Botella}

Doctora por la Universidad de La Coruña. Experta en Seguridad y Salud Laboral. Ha escrito diferentes artículos relacionados con esta materia en diversas revistas especializadas, y asimismo ha participado en diferentes proyectos de investigación.

\section{Miguel Clemente Díaz}

Catedrático de Psicología Social en la Universidad de A Coruña. Es experto en Psicología Jurídica, materia en la que ha escrito libros en editoriales como Pirámide, Biblioteca Nueva, EOS, Delta, y en esta última la obra Psicología Jurídica Laboral, y artículos en revistas como Aggressive Behavior, The Journal of Social Psychology, International Journal of Psychology, así como en revistas españolas de prestigio. Ha desarrollado proyectos de investigación sobre esta temática. Ha sido Presidente de la Sección de Psicología Jurídica de los Colegios Oficiales de Psicólogos de Madrid y de Galicia.

\section{Inmaculada Sangiao Bastida}

Graduada en Relaciones Laborales y Recursos Humanos y experta en Coaching. Investigadora en temas de educación y sensibilización sobre la temática de migración y derecho a refugio. Ha desarrollado diferentes actividades en organizaciones como Amnistía Internacional y en la primera edición del proyecto Acampa. 